\section{Quality and labeling information of Moringa oleifera products marketed for HIV-infected people in Zimbabwe}

\author{
Tsitsi Grace Monera-Penduka, ${ }^{1}$ \\ Zvinji Tella Jani, ${ }^{1}$ \\ Charles Chiedza Maponga, 1,2 \\ Josephine Mudzengi, ${ }^{3}$ Gene D. Morse, ${ }^{2}$ \\ Charles Fungai Brian Nhachi ${ }^{3}$ \\ ${ }^{1}$ School of Pharmacy, University of \\ Zimbabwe College of Health Sciences, \\ Harare, Zimbabwe; ${ }^{2}$ Pharmacy Practice, \\ State University of New York at Buffalo, \\ NY, USA; ${ }^{3}$ Department of Clinical \\ Pharmacology, University of Zimbabwe \\ College of Health Sciences, Harare, \\ Zimbabwe
}

\section{Abstract}

Labeling information and quality of marketed Moringa oleifera products were assessed. Personnel in 60 pharmacies and 11 herbal shops were interviewed about the sources, dosages, indications and counseling information of Moringa oleifera products. Content analysis of written information provided on Moringa oleifera products was also done. Three samples of Moringa from popular sources were acquired to determine heavy metal content and microbial contamination. The results were compared to specified limits in the European and Chinese pharmacopeia, World Health Organization guidelines and Bureau of Indian Standards. Moringa was available as capsules or powder in $73 \%$ of the premises. Moringa was recommended for seven different disease conditions. Four different dosage regimens were prescribed. The main references cited for the counseling information were unscientific literature (62\%). The selected Moringa samples were contaminated with bacteria and fungi above the European Pharmacopeia specified limits. Escherichia coli and Salmonella species were present in all three samples. All three samples contained arsenic, nickel and cadmium above the permissible limits. Moringa oleifera with variable labeling information and poor microbial and heavy metal quality is widely available in Zimbabwe.

\section{Introduction}

When herbal medicines are unregulated, consumers are potentially exposed to unsafe products. Safety issues may arise from circulation of inconsistent or unsubstantiated drug information, heavy metal residues, microbial contamination or adulteration. ${ }^{1,2}$ Heavy metal and microbial contamination is particularly of concern with HIV-infected individuals. Heavy metals could exacerbate the risk of liver and kidney damage associated with HIV-infection and treatment, while the microbial contamination may increase the risk of opportunistic infections due to a compromised immune system of HIV-infected people. ${ }^{3}$

In Zimbabwe, like many developing countries, regulation of the sale of herbal medicines is still in its infancy. The relevant statutory instrument was only gazette in September 2015. In addition, the national drug regulatory authority granted a transition period of one year before it would fully enforce the regulations. As a result, the impact of regulation is yet to be realized and unsafe herbal products may still be on the market. Very few studies have been conducted to assess potential safety issues with herbal products available on the market in Zimbabwe.

Assessing potential safety issues of commonly marketed herbal products would provide data to enable risk profiling of the herbs. The data would assist the drug regulatory agency when assessing herbal products for approval, to focus any analysis on relevant safety issues. The data would also serve clinicians as they counsel patients on herbal medicine use.

Moringa oleifera (drumstick/horseradish tree/moringa) is a herb commonly used as a nutritional supplement and immune enhancer by HIV-infected people in Zimbabwe. It is rich in nutrients including beta carotene, ascorbic acid, calcium, iron, proteins and carbohydrates and purported to have hypoglycaemic, hypotensive, hypocholesterolemic, anti-ulcer, antibacterial and anti-inflammatory activity. 4,5 While there is some evidence to support the health benefits of Moringa, very little is known about the safety of marketed Moringa products. This study was therefore undertaken to assess the labeling information as well as the heavy metal and microbial content of Moringa oleifera products in Zimbabwe.

\section{Materials and Methods}

\section{Study design and ethical considera- tions}

The study was a cross-sectional observational study incorporating laboratory assess-
Correspondence: Tsitsi G. Monera Penduka, Drug and Toxicology Information Services (DaTIS), School of Pharmacy, University of Zimbabwe College of Health Sciences, Harare, Zimbabwe. Tel.: +263.4307148.

E-mail: moneratg@yahoo.co.uk

Key words: Moringa oleifera; safety; labelling information.

Acknowledgements: the authors acknowledge laboratory assistance from the Medicines Control Authority of Zimbabwe and the Mining Research Institute of Zimbabwe staff.

Contributions: TM was responsible for the conception of the study, its design, drafting of the manuscript and analysis of data. JM and ZJ were responsible for data collection and contributed to the data analysis. $\mathrm{CM}$ and $\mathrm{CN}$ supervised the research process, revised the draft critically and gave final approval of the version to be published. GM contributed to the data analysis and revised the draft critically.

Conflict of interest: the authors declare no potential conflict of interest.

Funding: This publication was made possible by funding from the Department of Clinical Pharmacology, University of Zimbabwe College of Health Sciences as well as grant Number D43TW007991-01A2 from the Office of Global AIDS Coordinator and the U. S. Department of Health and Human Services, (National Institutes of Health (Fogarty International Centre). The two agencies funded the data collection. Its contents are solely the responsibility of the authors and do not necessarily represent the official views of the US government.

Received for publication: 2 November 2016. Accepted for publication: 11 november 2016.

This work is licensed under a Creative Commons Attribution NonCommercial 4.0 License (CC BYNC 4.0).

(C) Copyright T.G. Monera-Penduka et al., 2016 Licensee PAGEPress, Italy

Journal of Public Health in Africa 2016; 7:618 doi:10.4081/jphia.2016.618

ments. The research protocol was reviewed and approved by the Joint Parirenyatwa Hospital and College of Health Sciences Research Ethics Committee (Harare, Zimbabwe). Oral and written informed consent was obtained from supervising personnel at each of the premises after assurance of confidentiality.

\section{Sampling}

A convenience sample of 60 pharmacies and 11 herbal shops was selected. Three sam- 
ples of Moringa were purchased for determination of microbial and heavy metal contamination. One sample was from a pharmacy, another from a herbal shop and the third from an open market in Harare. Selection was based on the premises that had the highest reported monthly Moringa sales.

\section{Assessment of herbal medicine information}

Personnel were interviewed about the sources, dosage regimen, indications and counseling information of Moringa oleifera using a previously piloted interview script. Labels and available package inserts from Moringa products stocked in the premises were reviewed and data on indications, dosage regimen and cautionary messages were captured.

\section{Determination of microbial con- tamination}

The examination of microbial contamination was performed according to the harmonized microbial enumeration tests in the European Pharmacopeia. Enumeration of bacteria was carried out on tryptone soya agar, while that of fungi was done on sabouraud dextrose agar. All samples were diluted with buffered sodium chloride-peptone water, $\mathrm{pH}$ 7.0 to the concentration of $10^{-5}$. Subsequently, $1 \mathrm{ml}$ of each dilution was added to two sterile petri dishes of $10 \mathrm{~cm}$ diameter. For bacteria, tryptone soya agar was promptly added into each dish, mixed and the agar was allowed to set. After setting of the agar, the plates were incubated (Jeio Tech ${ }^{\mathrm{TM}}$ incubator; Jeio Tech Co., Ltd., Daejeon, Korea) at $30-35^{\circ} \mathrm{C}$ for three days. For fungi, Sabouraud dextrose agar medium was added to each dish, mixed and the content allowed to solidify. The plates were then incubated at $20-25^{\circ} \mathrm{C}$ for five days. The number of colonies for both bacteria and fungi was counted using a TRINITY V3 ${ }^{\mathrm{TM}}$ automated zone reader and colony counter (Giles Scientific Inc., Santa Barbara, CA, USA). All tests were carried out in duplicate. A negative control was performed for all tests with sterile peptone water $\mathrm{pH} 7.0$ used in place of the test preparation to verify testing conditions.

\section{Determination of specific microor- ganisms}

To determine contamination with enterobacteria in each sample, $10 \mathrm{~g}$ of the sample (weighed using Mettler PM 600 top loading balance) were added to $90 \mathrm{~mL}$ of Tryptone soya broth and mixed. After mixing, the material was incubated at $20-25^{\circ} \mathrm{C}$ for 2 hours. Nine $\mathrm{mL}$ of enterobacteria enrichment broth-Mossel were inoculated with $1 \mathrm{~mL}$ quantities of the product to be examined. The four resultant dilutions of the preparation which contained
$0.1 \mathrm{~g}, 0.01 \mathrm{~g}, 0.001 \mathrm{~g}$ and $0.0001 \mathrm{~g}$ of the product were incubated at $30-35^{\circ} \mathrm{C}$ for 24 hours. Each of the cultures was sub-cultured on a plate of violet red bile glucose agar and incubated at $30-35^{\circ} \mathrm{C}$ for 24 hours. Growth of colonies was examined. The smallest quantity of product that gave a positive result and the largest quantity that gave a negative result were noted. These results were used to determine the probable number of bacteria.

To determine contamination with Escherichia coli, $10 \mathrm{~g}$ of each sample was added to $90 \mathrm{~mL}$ buffered peptone water. Ten $\mathrm{mL}$ of the preparation was used to inoculate $90 \mathrm{~mL}$ of Tryptone soya broth, mixed and incubated at $30-35^{\circ} \mathrm{C}$ for 24 hours. The container with the material was shaken and $1 \mathrm{~mL}$ of tryptone soya broth was transferred to $100 \mathrm{~mL}$ of MacConkey broth and incubated at $42-44^{\circ} \mathrm{C}$ for 24 hours. The preparation was subcultured on a plate of MacConkey agar at $30-35^{\circ} \mathrm{C}$ for 24 hours. Growth of colonies was examined. To determine contamination with Salmonella, $25 \mathrm{~g}$ of each sample was added to $225 \mathrm{~mL}$ of buffered peptone medium, mixed and incubated at 30 $35^{\circ} \mathrm{C}$ for 24 hours. After incubation, $0.1 \mathrm{~mL}$ of buffered peptone water were transferred to 10 $\mathrm{mL}$ of Rappaport Vassiliadis Salmonella enrichment broth and incubated at $30-35^{\circ} \mathrm{C}$ for 24 hours. The material was subcultured on plates of xylose, lysine and deoxycholate agar. This was incubated at $30-35^{\circ} \mathrm{C}$ for 24 hours. Growth of bacteria was examined.

\section{Determination of heavy metal con- tamination}

Herbal medicine samples were digested through wet digestion. ${ }^{6}$ For all the samples, $5 \mathrm{~g}$ of the powdered sample was placed in a flask. Twenty $\mathrm{mL}$ of concentrated $\mathrm{HNO}_{3} 60 \%$ was added and heated on hot plate until product stopped producing brown fumes. Thirty $\mathrm{mL}$ of 1:1 solution of $\mathrm{HNO}_{3} 60 \%$ and perchloric acid $70 \%$ were added and heated until a suspension of approximately $1 \mathrm{~mL}$ was left in the flask. The residue was cooled and $5 \mathrm{~mL}$ of $0.5 \mathrm{M}$ HCL was added. Material was diluted with distilled water up to $25 \mathrm{~mL}$ and filtered through Whatman filter paper no. 42. The sample was then analyzed using the atomic absorption spectrometer (AAS) for chromium, cadmium, copper, lead, nickel, arsenic and zinc. The results were expressed in parts per million (ppm). The AAS operating parameters used were as shown below in Table 1.

\section{Statistical analysis}

The data were analyzed qualitatively and quantitatively using Stata ${ }^{11}$.

\section{Results}

\section{Source of Moringa oleifera products}

Moringa oleifera was sold in $73 \%$ of the premises. The Moringa was supplied by local farmers in $94 \%$ of the cases. One local open market were the farmers operate from was commonly cited by participants (90\%). A small proportion of the proprietors (4\%) sold their own cultivated supplies. Occasionally (10\%) Moringa was imported, mainly from a single South African phyto-pharmaceutical company.

\section{Labeling information available with Moringa oleifera products sold in Zimbabwe}

Moringa was recommended for seven different disease conditions including HIV infection, diabetes, hypertension, joint pain, prostate disorders, tuberculosis and arthritis. Four different dosage regimens were prescribed. The regimen prescribed did not vary with the conditions indicated and did not include the course duration. The main references cited for the counseling information were unscientific literature that included books, magazines and newspapers (Table 2).

\section{Microbial counts of Moringa samples}

All three samples were contaminated with aerobic bacteria and fungi above the European Pharmacopeia limits. Moringa from the herbal shop had the highest bacterial count while that from the pharmacy had the highest fungal count. The results are shown below in Table 3 .

\section{Presence of Salmonella species, Escherichia coli and enterobacteria \\ All three samples were contaminated with both Salmonella species and Escherichia coli. None of the samples were contaminated with bile tolerant gram-negative enterobacteria.}

Table 1. Instrumental parameters for heavy metal analysis.

\begin{tabular}{lccccccc} 
Element & $\mathrm{Cr}$ & $\mathrm{Cd}$ & $\mathrm{Cu}$ & $\mathrm{Ni}$ & $\mathrm{Pb}$ & $\mathrm{Znn}$ & $\mathrm{Ar}$ \\
Wavelength (nm) & 357.9 & 228.8 & 324.8 & 232 & 217.3 & 213.9 & 193.7 \\
Slit width (nm) & 0.2 & 0.5 & 0.5 & 0.2 & 1 & 1 & 1 \\
\hline Lamp current (mA) & 7 & 3.5 & 3.5 & 3.5 & EDL & 5 & EDL
\end{tabular}

EDL, electrodeless discharge lamp. Flame type was air-acetylene (BOC, South Africa). 


\section{Heavy metal contamination}

All three samples contained Arsenic, Nickel and Cadmium above the permissible limits. Lead, copper and zinc where within permissible limits. The results are shown in Figure 1A-F.

\section{Discussion}

Herbal therapy is rapidly developing within different cultures and regions of the world. As a result, there is likely to be variability in the composition, manufacturing processes and

Table 2. Labeling information available with Moringa oleifera products sold in Zimbabwe.

\begin{tabular}{lc} 
Description & Frequency \\
& $(\%)$ \\
Formulation sold & \\
Tablet & 0 \\
Capsule & 8 \\
Powder & 92 \\
Decoction & 0 \\
Part plant sold & \\
Bark & 44 \\
Leaves & 77 \\
Roots & 2 \\
Unknown & 8 \\
Indications & \\
Chronic & 71 \\
Acute & 29 \\
Recommended dosage regimen & \\
1 tsp daily & 31 \\
1 tsp $3 \times$ daily & 50 \\
1 cap daily & 6 \\
1 tbsp $3 \times$ daily & 19 \\
\hline Counseling messages & \\
Take with food & 52 \\
Take after food & 6 \\
Avoid when pregnant & 2 \\
None & 40 \\
Herbal drug information references & \\
Traditional knowledge & 10 \\
Unscientific literature & 62 \\
Supplier & 46 \\
Healthcare professional & 0 \\
\hline
\end{tabular}

clinical application of products of the same herb. ${ }^{7}$ In order to reduce the risk of adverse events attributable to unsafe herbal medicines, the WHO recommends the provision of minimum labeling information as well as assessment for contaminants of herbal products. ${ }^{8,9}$

Consistent with findings from previous studies, the labels reviewed in this study consisted of variable labeling information and generally lacked cautionary messages. ${ }^{10}$ The information is also likely to be biased given that the references were predominantly unscientific and were provided by the supplier in many of the cases. It was also interesting to note that traditional knowledge contributed to the information supplied on herbal products. This provides further evidence that opinions of traditional practitioners still have the potential to influence medication choices among Zimbabweans. ${ }^{11}$ Ideally, indications, dosage regimen and cautionary labels should be based on systematic reviews of rigorous clinical trials or documented history of clinical use in the case of traditional practices. ${ }^{12}$ A positive observation was that most of the labels indicated the parts of the plant that was sold. This is likely because of the ease of differentiation by color between plant part powders.

The three samples assessed in this study all had microbial loads above the recommended limits. This is a common finding in similar studies. ${ }^{13,14}$ In our case, since Moringa is a cultivated species in Zimbabwe, the herbal products may have been contaminated by microbes carried over from the soil or animal manure and waste used as fertilizers. Given that the herb was mainly supplied by local farmers who may not be trained in hygienic processing of herbs and operating from an open market, the contamination could also have been transferred from personnel during harvesting and processing of the plant material. Additionally, growth of microbes may have resulted from poor moisture control during drying or postharvest storage of plant material. ${ }^{15}$ Microbial contamination of Moringa products poses a significant risk for opportunistic infections in HIV-infected people because they often present late for antiretroviral therapy when their immune system is already severely compro- mised. Arsenic, cadmium and nickel levels in the samples evaluated were above the recommended limits. The findings are consistent with those from some previous studies but not others. ${ }^{16,17}$ The variation may be due to differences in cultivation environments since Moringa is known to absorb heavy metals from environments such as industrial and waste dumps during cultivation. ${ }^{18}$ Chronic exposure to arsenic can cause irritation of the stomach and intestines and decreased production of red and white blood cells. In addition, contamination with large amounts of arsenic can increase the chances of development of various cancers. ${ }^{19}$ Cadmium may be introduced into the environment through the use of fertilizers and sludge that contain cadmium. It has the potential to accumulate in the body due to its slow elimination (half-life of 20-30 years). Cadmium is associated with kidney toxicity and reduced bone mineral density. ${ }^{20}$ Moringa oleifera products contaminated with arsenic and cadmium could therefore potentially exacerbate problems associated with HIV-infection and treatment such as kidney, gastrointestinal and immune function as well as anemia and the risk of certain cancers. The Moringa samples analyzed had nickel levels marginally above the recommended limit. Nickel is relatively non-toxic in comparison with other metals. As such risk to nickel poisoning from Moringa consumption is considered minimal.

\section{Conclusions}

Moringa oleifera products assessed contain variable, unsubstantiated labeling information and were contaminated with bacteria, fungi, cadmium, arsenic and nickel above recommended limits. The contaminants may potentially exacerbate problems associated with HIV infection and treatment. Future regulatory assessments for approval of sale of Moringa oleifera products should priorities assessment of microbial burden as well as cadmium and arsenic levels. The contaminants may potentially exacerbate problems associated with HIV infection and treatment.

Table 3. Microbial counts in Moringa samples.

\begin{tabular}{|c|c|c|c|c|}
\hline Test & Source & Total aerobic microbial count (cfu/g) & Reference limit* & Comment \\
\hline Total aerobic microbial count of samples & $\begin{array}{l}\text { Pharmacy } \\
\text { Herbal shop } \\
\text { Open market }\end{array}$ & $\begin{array}{l}1 \times 10^{7} \\
3 \times 10^{7} \\
3 \times 10^{6}\end{array}$ & $\begin{array}{l}5 \times 10^{4} \\
5 \times 10^{4} \\
5 \times 10^{4}\end{array}$ & $\begin{array}{l}\text { Above limit } \\
\text { Above limit } \\
\text { Above limit }\end{array}$ \\
\hline Total fungal (yeasts and molds) count & $\begin{array}{l}\text { Pharmacy } \\
\text { Herbal shop } \\
\text { Open market }\end{array}$ & $\begin{array}{l}7 \times 10^{6} \\
5 \times 10^{6} \\
4 \times 10^{6}\end{array}$ & $\begin{array}{l}5 \times 10^{2} \\
5 \times 10^{2} \\
5 \times 10^{2}\end{array}$ & $\begin{array}{l}\text { Above limit } \\
\text { Above limit } \\
\text { Above limit }\end{array}$ \\
\hline
\end{tabular}

*European Pharmacopoeia. 
A 8

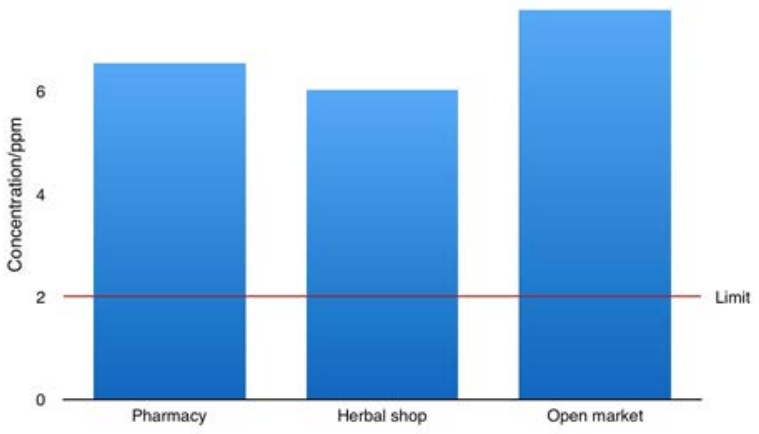

C

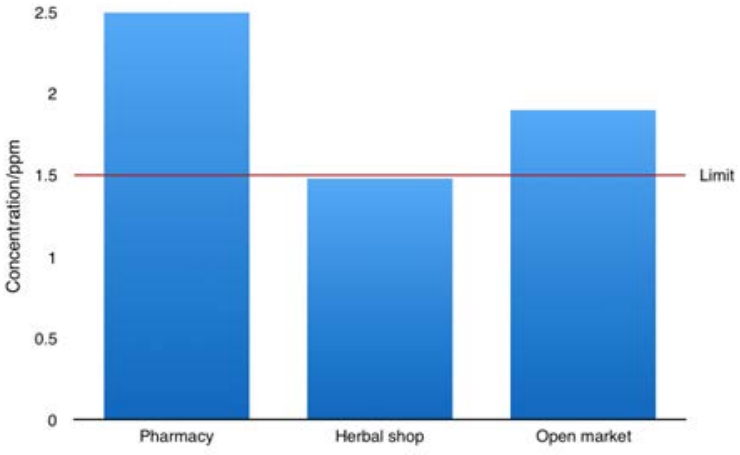

E

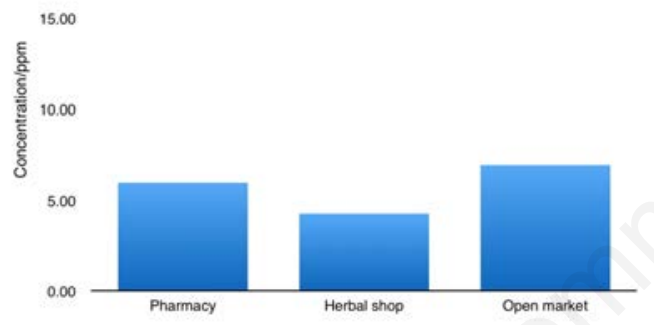

B 3.6

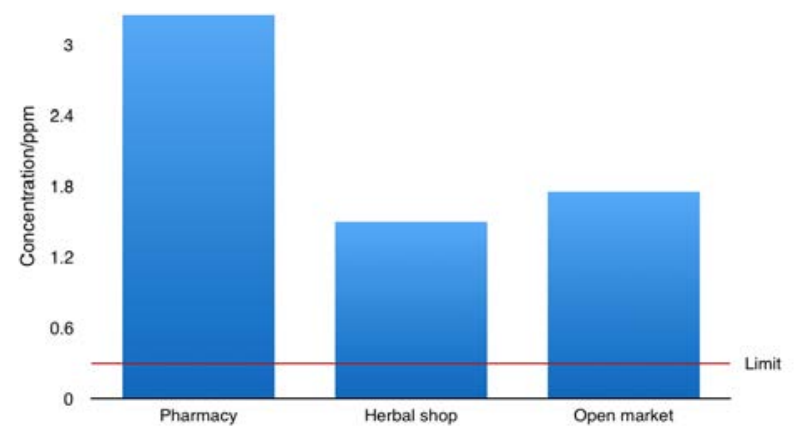

D - Limit
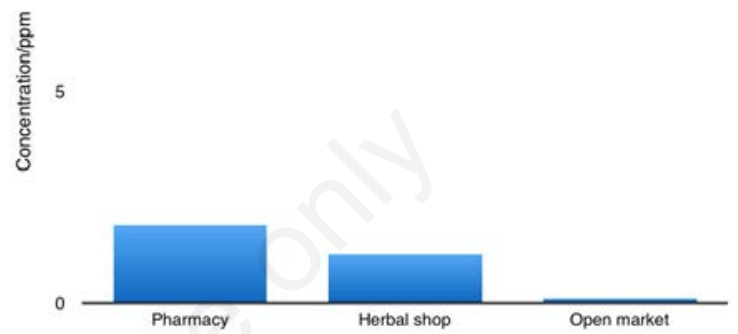

$\mathbf{F}$
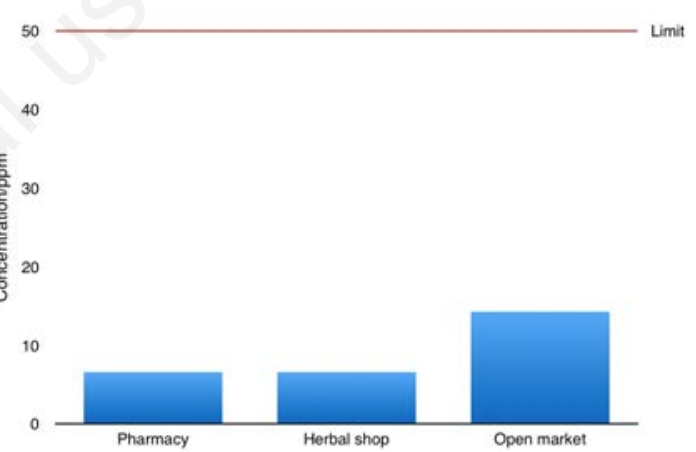

Figure 1. Concentration of $\mathrm{Ar}(\mathrm{A}), \mathrm{Cd}(\mathrm{B}), \mathrm{Ni}(\mathrm{C}), \mathrm{Pb}(\mathrm{D}), \mathrm{Cu}(\mathrm{E}), \mathrm{Zn}(\mathrm{F})$ detected in samples.

\section{References}

1. Clauson KA, Santamarina ML, Rutledge JC. Clinically relevant safety issues associated with St. John's worth product labels. BMC Complement Altern Med 2008;8:42.

2. Posadzki P, Watson L, Ernst E. Contamination and adulteration of herbal medicinal products (HMPs): an overview of systematic reviews. Eur J Clin Pharmacol 2013;69:295-307.

3. Lorenc A, Robinson N. A review of the use of complementary and alternative medicine and HIV: issues for patient care. AIDS Patient Care STDS 2013;27:503-10.

4. Anwar F, Ashraf M, Gilani AH. Moringa oleifera: a food plant with multiple medicinal uses. Phytother Res 2007;21:17-25.
5. Mudzviti T, Maponga CC, Khoza S et al. The impact of herbal drug use on adverse drug reaction profiles of patients on antiretroviral therapy in Zimbabwe. AIDS Res Treat 2012;2012:434171.

6. Elmer P. AY-5 analysis of plant tissue wet digestion. In: Crop PE, ed. Operational manual: atomic absorption spectrophotometer. 1991.

7. World Health Organization. WHO National policy on traditional medicine and regulation of herbal medicines. Report of a WHO global survey. 2005. Available from: http://apps.who.int/medicinedocs/pdf/s791 6e/s7916e.pdf

8. World Health Organization. Guidelines for the appropriate use of herbal medicines. Geneva: WHO Regional Publications; 1998. Available from: http://apps.who.int/medi-
cinedocs/en/d/Jh2945e/

9. World Health Organization. WHO guidelines for assessing quality of herbal medicines with reference to contaminants and residues. World Health Organization; 2007. Available from: http://apps.who.int/ medicinedocs/index/assoc/s14878e/s14878 e.pdf

10. Raynor DK, Dickinson R, Knapp P et al. Buyer beware? Does the information provided with herbal products available over the counter enable safe use? BMC Med 2011;9:1-9.

11. O'Brien S, Broom A. HIV in (and out of) the clinic: biomedicine, traditional medicine and spiritual healing in Harare. Sahara J 2014:94-104.

12. World Health Organization. Guidelines for clinical study of traditional medicines in 
the WHO Africa region. 2004. Available from: http://apps.who.int/medicinedocs/ documents/s21350en/s21350en.pdf

13. Adu-Gyamfi A, Mahami T. Effect of drying method and irradiation on the microbiological quality of moringa leaves. Int J Nutr Food Sci 2014;3:91-6.

14. Shehu K, Maishanu AM, Salau IA. A preliminary study on microbial contamination of leafy vegetables in Sokoto Metropolis, Nigeria. Aceh Int J Sci Technol 2014;3:1404.

15. Sauveur A, Broin M. Growing and processing Moringa leaves. Moringa and Plant
Resources Network 2010:55-63.

16. Offor IF, Ehiri RC, Njoku CN. Proximate Nutritional analysis and heavy metal composition of dried Moringa Oleifera leaves from Oshiri Onicha L.G.A, Ebonyi State, Nigeria. OSR J Environ Sci Tox Food Tech 2014;8:57-62.

17. Limmatvapirat $\mathrm{C}$, Limmatvapirat $\mathrm{S}$, Charoenteeraboon $\mathrm{J}$ et al. Comparison of eleven heavy metals in Moringa Oleifera Lam. products. Indian J Pharmaceut Sci 2015;77:485-90.

18. Moringa Association of Ghana. Growing and processing moringa leaves. Accra:
Moringa and Plant Resources Network; 2010.

19. Agency for Toxic Substances and Disease Registry. Toxicological Profile for Arsenic. 2007. Available from: https://www.atsdr. cdc.gov/toxprofiles/TP.asp?id=22\&tid=3.

20. Agency for Toxic Substances and Disease Registry. Toxicological Profile for Cadmium. Atlanta: U.S. Department of Health and Human Services; 2012. Available from: http://www.atsdr.cdc. gov/ToxProfiles/TP.asp?id=48\&tid=15. 